\title{
A Methodical Formative Evaluation of Computer Literacy Course: What and How to Teach
}

\author{
Florence Martin \\ University of North Carolina, \\ Wilmington, NC, USA
}

florencemartin@gmail.com

\author{
Qi Dunsworth \\ Penn State Erie, \\ The Behrend College, \\ Erie, PA, USA
}

QiDunsworth@psu.edu

\section{Executive Summary}

The use of computers has become pervasive and essential in today's world. Most of the universities offer a basic computer literacy course to the students. To meet the demand of computerliterate graduates, it is important to determine what constitutes a desired computer literacy course and how they should be taught. Formative evaluation of computer literacy should be conducted at universities so that the courses that are offered match up with the requirements of the students and also align with technological advances and employer requirements.

The focus of research in this current study is to formatively evaluate a computer literacy course offered by the Educational Technology program at a large southwestern United States university. In this course, students are given an introduction to computers and software applications they will use in their professional and personal lives. The feelings of both the students and the instructors of the course toward the content taught, the skills learned and the instructional strategies used were measured by the formative evaluation process. The evaluation focused on the following questions:

- Do the academics and the students agree on the optimal content of a basic computer literacy course?

- Do the academics and the students agree on the optimal instructional strategies to teach the content?

Data collection tools such as student and instructor surveys, student, instructor and coordinator interviews, class observations, and student test scores were used. The results are categorized into two main areas: 1) what to teach and 2) how to teach it. Among the different skills listed in the survey, Microsoft Office Skills (Word, Excel and PowerPoint) were rated most useful by both students and instructors. File management skills were rated as less useful by students. Theoretical content on hardware of the computer was rated the least useful topic by both students and instruc-

Material published as part of this publication, either on-line or in print, is copyrighted by the Informing Science Institute. Permission to make digital or paper copy of part or all of these works for personal or classroom use is granted without fee provided that the copies are not made or distributed for profit or commercial advantage AND that copies 1) bear this notice in full and 2) give the full citation on the first page. It is permissible to abstract these works so long as credit is given. To copy in all other cases or to republish or to post on a server or to redistribute to lists requires specific permission and payment of a fee. Contact Publisher@InformingScience.org to request redistribution permission. tors. Hands-on projects and in-class activities were the most helpful strategies according to both instructors and students. Long lectures and online quizzes were rated as less helpful teaching strategies by students, but the instructors thought that they were helpful. Teaching Excel and web page creation needed more demonstrations and directions. Based on the results of the formative evaluation, some recommendations were 
given to the faculty coordinator. The findings of the evaluation have implications for all the universities in which basic computer literacy courses are offered.

Keywords: Computer Literacy, Formative Evaluation, Evaluation, Microsoft Office, Computer Skills, Teaching Strategies

\section{Introduction}

Evaluation is the process of gathering information that will facilitate improving a program (formative) or that will help determining its value (summative). Many experts have analyzed the difference between formative and summative evaluation. Markle (1989) stated that summative evaluation is an evaluation to prove but formative evaluation is an evaluation to improve the programs or the product. According to Baker and Alkin (1973), summative evaluation is the evaluation for validation while formative evaluation is the evaluation for revision.

The term "formative evaluation" was coined by Scriven (1967) and is the process of collecting qualitative or quantitative data during the developmental stage of the instructional design process (Seels \& Glasgow, 1990). The data collected is used to provide immediate feedback and helps to make revisions or modifications to the program before the final product is developed. One can evaluate almost anything, such as a person, a curriculum, a student, a process, a product, or a program (Tessmer, 1993). In the process of instructional development, the instructional designer evaluates the instructional materials to determine weaknesses in the instruction so that the material can be modified (Smith \& Ragan, 1999).

In this study, the focus of research is a formative approach where an evaluation is done to improve the curriculum design of computer literacy rather than a summative evaluation to prove the overall effectiveness of the curriculum. Formative evaluation of the course helped the instructors identify if the students achieved sufficient mastery of skills in the curriculum for the course, or if further instruction was needed in specific areas. It also helped to identify if both the instructors and students agreed on the importance of the instructional content and strategies of the course.

\section{Formative Evaluation in Computer Literacy}

Computer literacy has been defined as "an understanding of computer characteristics, capabilities, and applications, as well as an ability to implement this knowledge in the skillful, productive use of computer applications suitable to individual roles in society" (Simonson, Mauere, MontagToradi, \& Whitaker, 1987, p. 233). Gupta (2006) defines it as the individual's ability to operate a computer system. This includes having a basic understanding of the file management processes such as formatting a disk and how to save, copy, delete, open, and print documents. It also involves using computer applications software to perform personal or job-related tasks, using web browsers and search engines online, and being able to email.

Computer literacy is a fundamental part of the undergraduate curriculum in this decade. It is as basic to undergraduate students as the course work in the core curriculum (Dugger, Meade, Delany, \& Nichols, 2003). Students educated in computer literacy use the computer skills in most of the other courses in their discipline. Previous studies have found that computer competency is essential to both academic and career achievement (Davis, 1999).

Many studies have discussed the contents of computer literacy course and instructional strategies in terms of learning effectiveness. An "all-purpose computer literacy" class that expects everything to be taught in one semester is considered unrealistic (Beard, 1993). According to Ndahi and Gupta's study (2000) on workforce training, the most frequently required computer skills 
were word processing and the knowledge of database software. In addition, the trainees voiced a strong interest in learning file management and preparing presentations. Gupta (2006) found that basic parts and functions of information systems, system software, security and privacy issues, the use of application software (word processor, using a spreadsheet, preparing a presentation), and accessing remote computers should be among the course objectives of a basic computer literacy course.

According to Lankshear and Knobel (2003), some of the new computer literacies include electronic gaming, synchronous and asynchronous communication, weblogs, webpages, and multimedia text production. Andrews (2004) researched the new literacies in computer technologies including the environment in which students learn how to read and write with multiple modalities (graphics, animations, video, audio, hyperlinks, and print).

Wambach (2006) states that in order to achieve computer proficiency, students tend to collaborate on classroom projects and work on annual inquiry projects by using the Internet and demonstrating their computer presentation skills. Wambach also concluded from his research that whatever type of computer system is used (such as desktops, laptops, or tablets) and wherever the computer is used (in a lab, on a wireless cart, or on a bedroom desk), students desire to have one-to-one access and consider computers as learning tools, as essential as a pencil or calculator.

Computer-based instruction and Web-based instruction with interactive practice activities are found to be effective methods to teach computer literacy (Martin, Klein \& Sullivan, 2004, 2006). The idea of adaptive, computer-based instruction in which students learn from intelligently iterating through interactive lessons also seems to be an emerging trend in computer literacy (Doe, 2005). Another strategy that is becoming popular is using instructional games to teach computer literacy (Squire \& Steinkuehler, 2005).

With the changes in technology, the different elements of computer literacy are prone to change constantly and hence it is important for educators to constantly revise the course to include the latest technology advancement. The rapid pace of technological advances in the computer industry has also forced businesses to reorganize, to acquire the latest systems, and demand a computer-literate workforce (Porter \& Miller, 1985). Therefore, they seek computer literacy in almost everyone they hire (Ndahi \& Gupta, 2000). To meet the demand of computerliterate graduates, it is important to determine what constitutes desired computer competency skills and how they should be taught. Formative evaluation should be done at universities so that course goals align with student requirements, technological advancement, and employer requirements

\section{The Computer Literacy Course}

This course is an undergraduate computer literacy course offered by the Educational Technology program at a large southwestern U.S. university. In this course, students are given a solid introduction to computers and the software applications they will use in their professional and personal lives.

The course is conducted in a learner-centered classroom, which requires active student participation. The instruction features illustrated lectures, in-class discussions, on-line research and discussion, student-generated information, demonstrations, and hands-on lab activities. This is a general studies required course, and students from different majors campus wide were enrolled. During the evaluation semester, there were 21 sections with a total of 444 students enrolled. There were 11 teaching assistants who taught the 21 sections and a faculty member who coordinated all these sections. 
The course has two areas of concentration: theoretical knowledge about computers, and knowing how to use computer applications for productivity, problem solving, and data analysis. It is a semester-long course and the students meet once a week for three hours.

\section{Purpose of the Formative Evaluation}

The purpose of this evaluation was to measure the effectiveness of the course by evaluating the content taught and the instructional strategies used in the course, and to identify if both the academics and the students agreed on the importance on the course content and instructional strategies used to teach the course. The effectiveness of the course was found by measuring the student and instructor perception of usefulness of different topics taught and helpfulness of teaching strategies used. The summative assessment performance data of the students from quizzes and a midterm exam was also analyzed to assess the students' learning in the process of formative evaluation.

The evaluation focused on the following questions:

- Do the academics and the students agree on the optimal content of a basic computer literacy course?

- Do the academics and the students agree on the optimal instructional strategies to teach the content?

\section{Method}

\section{Participants}

The participants in the evaluation were the students, instructors, and coordinator of the computer literacy course. All the 444 students enrolled in the course were surveyed using a survey uploaded through the Blackboard Course Management System. Twenty-five students from five different sections were interviewed in focus groups. The 11 instructors who had been teaching this course were surveyed and five of the instructors were interviewed. The coordinator of the course was also interviewed. Based on the different data sources, different procedures were used in evaluation as explained in the next section.

\section{Data Sources}

A variety of data sources were investigated and recommendations were made based on the results of the data collected. The feelings of both the students and the instructors of the course toward the content taught as well as the instructional strategies used in this course were noted.

\section{Survey}

An online survey was distributed through the course Blackboard. The survey was sent to 444 students from the 21 sections, and 329 responses were received. The instructors were surveyed using a paper-based survey. There were two categories of questions on the survey (feelings toward topics covered and feelings toward teaching strategies used) which were the same for both the students and the instructors. The respondents had to rate the questions on a four-point Likert scale that varied for the two categories. For the "usefulness of content" category, the Likert scale was Very Useful $=3$, Useful=2, Less Useful $=1$ and Not Useful=0. For the "helpful strategies" category, the Likert scale was Very Helpful $=3$, Helpful $=2$, Less Helpful $=1$ and Not Helpful $=0$. The student survey can be found in the Appendix. 


\section{Interview protocol}

Twenty-five students who volunteered were interviewed in five focus groups with five students in each focus group. Five instructors who volunteered were interviewed in person individually. The students and the instructors were interviewed with similar questions on the topics covered and teaching strategies used in the course. The coordinator of the course was interviewed on her feelings about the content and skills taught and the instructional strategies used in the course. The two evaluators conducting the interviews were doctoral students in the educational technology program.

\section{Test scores}

Student performance in the quizzes and midterm were noted to analyze the content. There were four online quizzes that were used to test student performance. These four quizzes covered the major topics of the course (Quiz 1-File Structures, Word, Internet; Quiz 2 -Input, Processing, Storage, Output; Quiz 3- Excel and Data Analysis; Quiz 4- PowerPoint). The content covered during the first half of the semester was tested by a midterm exam.

\section{Class observations}

Observations were made in five classes to collect data on the instructional strategies used and on the content taught in the class. Most of the classes had lectures and in-class activities. The inclass activities and hands-on projects helped evaluate the skills learned by the students. Observations were made by two doctoral students in the educational technology program. Five classes were selected in a random manner. The evaluators had an observation schedule and one of the evaluators observed two classes and the other observed three.

\section{Results}

\section{What to teach?}

\section{Survey results}

Both the students' and the instructors' feelings toward topics taught in this computer literacy course were collected through the survey. The weighted mean of the responses obtained from students and instructors were tabulated and also depicted by graphs. Seven main topics that were taught in the course were listed on the survey (Word, Excel, PowerPoint, WebPages, Internet and World Wide Web, File Structure, and IPSO (Input, Processing, Storage and Output). Students and instructors rated these topics on a four point Likert scale on the level of usefulness (Very Useful $=3$, Useful $=2$, Less Useful $=1$ and Not Useful=0). The results are shown in Table 1 .

The mean score of the student ratings was 2.08 as opposed to 2.44 for the instructor ratings. Word was rated as the most useful by students $(\mathrm{M}=2.53)$ and PowerPoint was rated as the most useful by the instructors $(\mathrm{M}=2.82)$. The least useful topic according to the students $(\mathrm{M}=1.53)$ and the instructors $(\mathrm{M}=1.64)$ was IPSO. The ratings of the topics can be analyzed from the graph in Figure 1 . The students rated all the topics slightly less useful than the instructors. The top three topics rated by both the instructors and students were Word, PowerPoint, and Internet and worldwide web. 
Table 1: Student and Instructor Survey Mean Scores on the Usefulness of Content

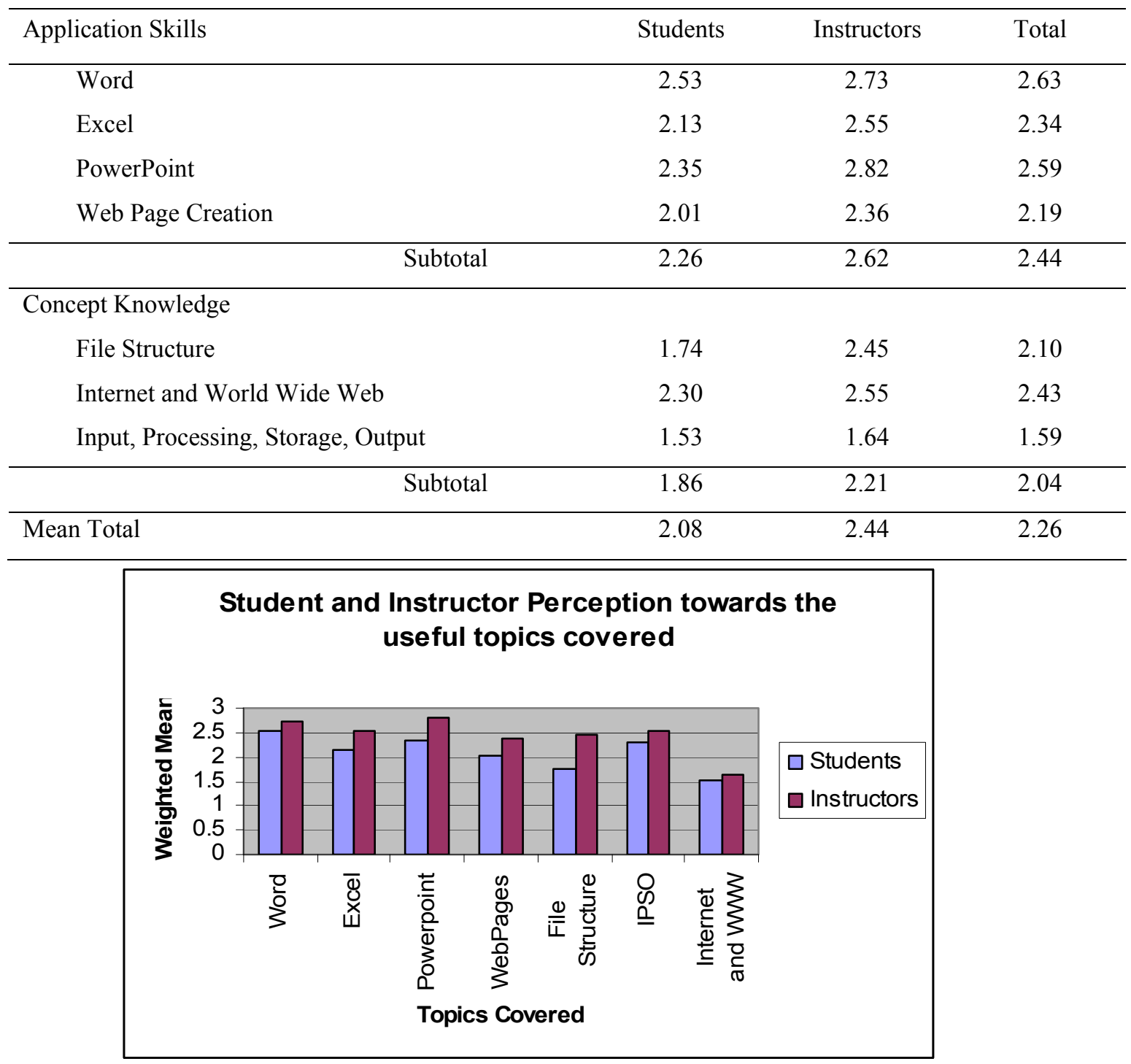

Figure 1: Analysis of students' and instructors' perception toward topics covered

\section{Interview results}

All five student focus groups expressed Word and PowerPoint to be useful topics, and four focus groups considered Excel to be useful. The instructors considered Word, PowerPoint, and File Management skills to be the most useful topics taught. Both the students and instructors agreed that the students needed more practice on file management skills and that web page creation was a difficult topic, and a job aid might be helpful to them. Students thought that Excel was a helpful skill even though it was difficult.

The coordinator mentioned that the main aim of the course was to make the students competent enough to use the computer. All the Microsoft Office skills that were taught are useful to the students. More instructional content on visual and information literacy was recommended to be added to the course. 


\section{Student performance in quizzes and midterm}

The students' performance in the different quizzes helped perform an analysis of student learning on the different topics taught. These four quizzes covered the major topics of the course (Quiz 1File Structures Word, Internet; Quiz 2 - IPSO; Quiz 3- Excel and Data Analysis; Quiz 4- PowerPoint). The content covered during the first half of the semester was tested in the midterm exam. The performance of students from all the sections was comparatively better on Quiz 2 (Input, Processing, Storage and Output) and Quiz 3 (Excel and Data Analysis). Quiz 1 (File Structures, Word, Internet) and Quiz 4 (PowerPoint) had relatively lower results.

A maximum of 10 points could be scored on each quiz and 30 points on the midterm and final. For all 21 sections, Quiz 1 had a mean of 6.85, Quiz 2 had 8.14, Quiz 3 had 8.10 and Quiz 4's mean was 7.00. In the midterm exam the mean scores of the sections ranged from 21.24 to 25.23. The mean midterm score for all the 21 sections was 22.83 , which was $76.1 \%$. On the hands-on finals the mean score was 25.55 , which was comparatively good at $85.17 \%$. (See Table 2 .)

Table 2: Mean Analysis of the Quiz and Midterm Scores

\begin{tabular}{ccccccc}
\hline Section & $\begin{array}{c}\text { Quiz 1 } \\
\text { Files/Word/Internet }\end{array}$ & $\begin{array}{c}\text { Quiz 2 } \\
\text { IPSO }\end{array}$ & $\begin{array}{c}\text { Quiz 3 } \\
\text { Excel }\end{array}$ & $\begin{array}{c}\text { Quiz 4 } \\
\text { PowerPoint }\end{array}$ & Midterm & Finals \\
\hline Mean & 6.85 & 8.14 & 8.10 & 7.00 & 22.83 & 25.55 \\
$\%$ & $68.5 \%$ & $81.4 \%$ & $81 \%$ & $70 \%$ & $76.1 \%$ & $85.17 \%$ \\
\hline
\end{tabular}

Student performance in Quiz 1 was the lowest, though they mentioned that it was the easiest topic. It was mentioned in the interview that this was due to the fact that it was the first time they were taking an online multiple choice quiz in this class and were not sure about the detail to which they would be tested on. They also performed poorly on Quiz 4 because of the detail in which they were tested on PowerPoint, though it was an easy topic. Though the students thought that IPSO was not very useful to them, they performed well on the IPSO Quiz. They performed well on Quiz 3, which was on Excel. It was expressed by the students and instructors that the nature of the questions on Excel was more application-focused and the quiz gave them an opportunity to work on an Excel sheet before answering the questions.

\section{How to teach? Survey results}

Nine instructional strategies that were used in the course (hands-on projects, in-class activities, handouts and directions, PowerPoint presentations, online quizzes, external website links, group work, discussion forums and textbook readings) were listed on the survey. Students and instructors rated these strategies on a four-point Likert scale on the level of helpfulness (Very Helpful = 3, Helpful $=2$, Less Helpful $=1$ and Not Helpful $=0$ ). (See Table 3)

Students $(\mathrm{M}=2.52)$ and instructors $(\mathrm{M}=2.91)$ agreed that the hands-on approach was the most helpful instructional strategy, followed by in-class activities (students $=2.28$, instructors $=2.64$ ) and handouts and directions (students $=2.27$, instructors $=2.55$ ). The students and instructors also agreed that the three least helpful strategies were readings from textbooks (students $=0.73$, instructors $=1.09$ ), discussion forums ( students $=1.22$, instructors $=0.82)$ and group work (students $=1.34$, instructors $=1.27$ ). The other strategies such as PowerPoint presentations, online quizzes, and external website links received intermediate ratings. 
Table 3: Analysis of Student and Instructor Perception towards Teaching Strategies Used

\begin{tabular}{|c|c|c|}
\hline Strategies Used & Students & Instructor \\
\hline Hands-on Projects & 2.52 & 2.91 \\
\hline In-class activities to develop practical skills & 2.28 & 2.64 \\
\hline Handouts and directions for different activities and projects & 2.27 & 2.55 \\
\hline PowerPoint presentations to deliver lecture & 2.12 & 1.82 \\
\hline Online Quizzes and Midterm & 1.84 & 2.09 \\
\hline External Website Links & 1.69 & 1.64 \\
\hline Co-operative Group work & 1.34 & 1.27 \\
\hline Discussion Forums & 1.22 & 0.82 \\
\hline Readings from Textbooks & 0.73 & 1.09 \\
\hline Mean Total & 1.78 & 1.87 \\
\hline
\end{tabular}

For the helpfulness of all the strategies used, the total mean was reported as 1.78 by students and 1.87 by instructors. The graphical representation of the responses of the students and the instructors toward the helpfulness of the teaching strategies is represented in Figure 2.

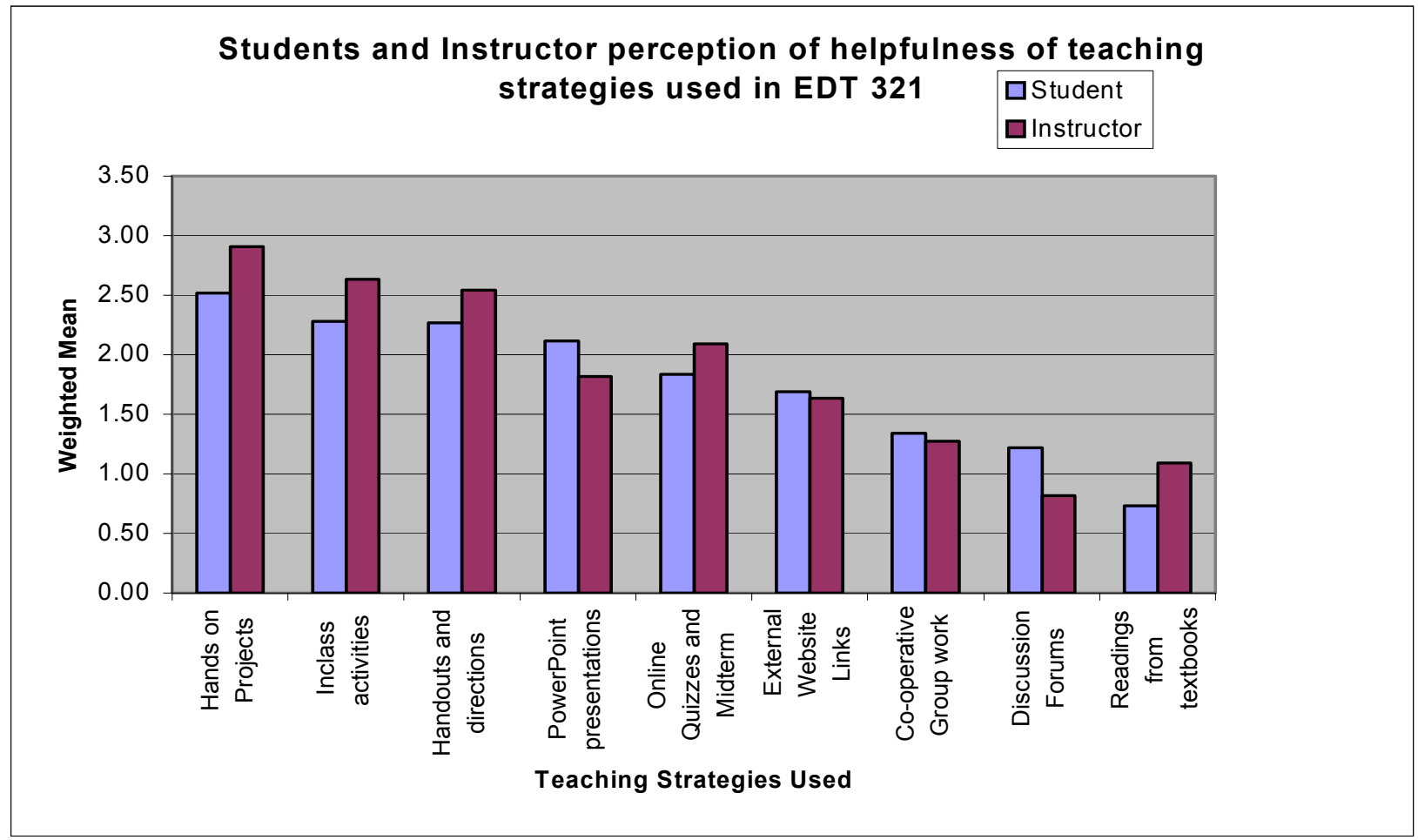

Figure 2: Analysis of students' and instructors' perception of helpfulness of teaching strategies used in Computer Literacy Course 


\section{Interview results}

All the student focus groups mentioned that the in-class activities were the most helpful strategies and four focus groups thought that hands-on projects were helpful. Instructors agreed with the students and mentioned that hands-on projects and in-class activities were the most helpful strategies used. The well-designed Power Point lectures and the online quizzes were also thought to be helpful by some of the instructors. Students and instructors thought that the readings from the textbook did not help in reaching the course objective. The coordinator also mentioned that the labs should be upgraded with the latest technology and students should also be taught more online and Blackboard skills.

\section{Class observations}

Classroom observations revealed that students seemed to dislike long PowerPoint presentations that instructors used to deliver lectures. Here again, the students liked the in-class activities and hands-on projects. Students did not like the online quizzes and midterm, but the instructors felt that this strategy was useful to measure student learning. Students liked the hands-on finals that tested their skills. There was much interaction between the instructor and the students, and the students were helped individually when they encountered difficulties.

\section{Open ended question analysis}

There was an open ended question on the survey on areas of improvement in the course. The top five suggestions given by the students were 1) No changes required and they were satisfied with the content taught, 2) More than one instructor was needed for a class size of 18-24 as it was difficult to get individual assistance when working on projects, 3) The text book assigned was not helpful and more activities were preferred than readings, 4) The class should slow down, especially on the difficult topics, 5) Preferably, the lectures were made shorter.

\section{Discussion \& Recommendation}

Formative evaluation was conducted in this computer literacy course and specific areas such as the topics and skills taught, and the teaching strategies used were evaluated. Data were collected from different sources and were analyzed. The instructional material used to teach was liked by both the students and the instructors. The data collected from the student and instructor surveys gave their perception of usefulness of topics and skills taught, and helpfulness of teaching strategies used.

Word, PowerPoint, Excel, and Internet and World Wide Web were highly rated as useful topics by both instructors and students. Microsoft Office skills are required for many jobs these days and have become a part of everyday life. These skills also assist students in their other classes. Hence the students tended to rate these skills as very useful. The theoretical content on Internet and World Wide Web was thought to be very helpful by both the students and instructors, whereas the theoretical content on computer hardware (IPSO) was rated low. It is assumed that being in the Internet Age, students and faculty realized the importance of the concepts on how the Internet and the World Wide Web work. However, they did not think that it was very important for them to know what was inside a computer. File Management received a low rating by students but a high rating by the instructors. This shows that the instructors realized the importance of file management skills for students, whereas the students did not realize the importance. More practice activities designed to teach file management skills were recommended by the instructors.

Hands-on projects and in-class activities were the most helpful strategies according to both instructors and students. Long lectures and online quizzes were disliked by students, but the instructors thought that the lectures and quizzes were helpful strategies. The students considered the 
quizzes to be very detailed. This shows that students prefer the hands-on approach to learning. Teaching Excel and web page creation needed more demonstrations and directions. Discussion forums and readings from text books received the lowest rating by both the students and the instructors.

From the class observations, it was understood that it was hard for the instructor to help each of the 18-24 students when they encountered difficulties. So having an assistant to the instructor in larger classes is advisable. Clear directions and handouts are needed for the projects and in-class activities. More collaborative activities would allow students to learn from each other. Analysis of the course materials showed that the text book was inappropriate for the class, and that the discussion forum must be redesigned with clearer directions and more time assigned in class to work on it.

Based on the results of the formative evaluation, some recommendations were given to the faculty coordinator. The findings of the evaluation have implications on the computer literacy curriculum design for all universities in which basic computer literacy courses are offered. Some implications are not surprising. For examples, hands-on projects are more effective than lectures and textbooks in teaching practical skills. An implication that is more noteworthy is that instructors may need to find creative methods to impress upon students the importance of file management systems.

\section{References}

Andrews, R. (Ed.) (2004). The impact of ICT on literacy education. London: Routledge Falmer.

Baker, E. L. \& Alkin, U.C. (1973) Formative evaluation of instructional development. Audio Visual Communication Review, 21(3), 300-305

Beard, C. (1993). Transfer of computer skills from introductory computer courses. Journal of Research on Computing in Education, 25(4), 413-430

Davis, P. (1999). How undergraduates learn computer skills: Results of a survey and focus group. THE Journal, 26(9), 68-71.

Doe, C. (2005). Technology and textbooks: Cutting-edge early literacy technology. MultiMedia \& Internet at Schools, 12(5), 26-29,

Dugger, W. E., Meade, S. D., Delany, L. \& Nichols, C. (2003). Advancing excellence in technological literacy. Phi Delta Kappan, 8(4), 316.

Gupta, G. K. (2006). Computer Literacy: Essential in Today's Computer-Centric World. ACM SIGCSE Bulletin, 38, 2, 115-119

Lankshear, C. \& Knobel, M. (2003). New literacies: Changing knowledge and classroom learning. Buckingham: Open University Press.

Markle, S. M. (1989). The ancient history of formative evaluation. Performance and Instruction, Aug, 2729

Martin, F., Klein, J. D. \& Sullivan, H. (2004). Effects of instructional events in computer-based instruction. Proceedings of the Association for Educational Communications and Technology, Chicago, 19-23 October.

Martin, F., Klein, J. D. \& Sullivan, H. (2006). The impact of instructional elements in computer-based instruction. British Journal of Educational Technology (OnlineEarly Articles).

Ndahi, H. \& Gupta, A. (2000). Computer literacy for workforce development. Reading Improvement, $37(1), 39-44$.

Porter, M.E. \& Miller, V. E. (1985). How information gives you competitive advantage. Harvard Business Review, 63(4), 149-160. 
Scriven, M. (1967). The methodology of evaluation (AERA Monograph series on curriculum evaluation, No. 1). Chicago IL: Rand McNally.

Seels, B. \& Glasgow, Z. (1990). Exercises in instructional design. Columbus, Ohio: Merrill Publishing Company.

Simonson, M.R., Maurer, M., Montag-Torardi, M. \& Whitaker, M. (1987). Development of a standardized test of computer literacy and a computer anxiety index. Journal of Educational Computing Research, $3(2), 231-247$.

Smith, P. L. \& Ragan, T. J. (1999). Instructional design (2nd ed.). Upper Saddle River, New Jersey: Merrill.

Squire, K. \& Steinkuehler, C. (2005). Meet the gamers. Library Journal, 130(7), 38-41

Tessmer, M. (1993). Planning and conducting formative evaluation. London: Kogan Page Limited.

Wambach, C. (2006). From revolutionary to evolutionary: 10 years of 1-to-1 computing. $T$ H E Journal, 33,14 .

\section{Appendix Computer Literacy Course Evaluation - Student Survey}

A. The questions A1-A7 are the topics taught in the course EDT 321. To what extent are these topics useful to you? Rate them on the scale given.

$3=$ Very Useful $2=$ Useful $\quad 1=$ Less Useful $\quad 0=$ Not Useful

A1.Word

A2. Excel

A3. PowerPoint

A4. Webpages

A5. File Structure

A6. IPSO

A7. Internet and World Wide Web

B. Questions from B1-B9 are the teaching strategies used in EDT 321. How helpful were these strategies to you in learning?

Very helpful $=3$ Helpful $=2$ Less Helpful $=1$ Not helpful $=0$

B1.PowerPoint presentations to deliver lecture

B2.Readings from textbooks

B3.Handouts and directions for different activities and projects (Skills checklist, hyperlink handout, web evaluation criteria handout etc.)

B4.Hands-on Projects (Word, Excel, PowerPoint, Webpages)

B5.In-class activities to develop practical skills (Mail merge, Table of Contents, Scavenger Hunt, Web evaluation etc.)

B6.Discussion forums

B7.External Website Links

B8.Online Quizzes and Midterm 
B9.Co-operative Group work

C. Would you change anything for the instruction for any of the topics taught in EDT 321? How about the different strategies used in teaching? Would you change any strategy used? Do you prefer any change in the skills taught?

\section{Biographies}

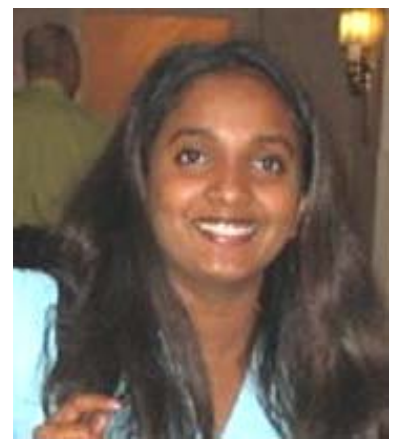

Florence Martin is currently an instructional design consultant with Mesa Community College and University of Phoenix. She is starting this fall as an assistant professor in instructional technology at the University of North Carolina, Wilmington. She is interested in the research areas of educational gaming and simulation, instructional alignment, process and performance improvement, learning management systems and virtual classrooms. She is a graduate of the doctoral program in educational technology at Arizona State University. She has worked with Cisco Learning Institute, Intel and Arizona State University and has expertise in instructional design, performance technology, corporate training and distance learning.

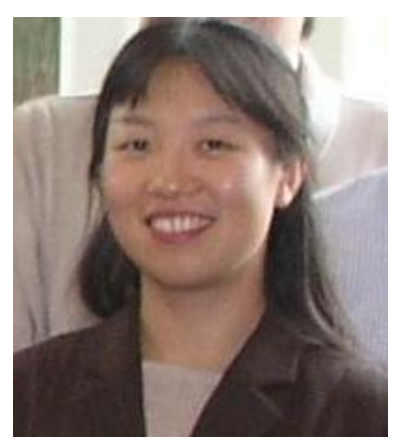

Qi Dunsworth is an instructional designer at Penn State Erie, The Behrend College. She is in charge of faculty support and professional development, and organizes and presents college teaching seminars. Her research interests include effective use of visual and auditory instruction, instructional design for quality online courses, and teaching strategies incorporating new technology. She holds a graduate degree in Communication Studies and earned her Ph.D. in Educational Technology from Arizona State University. 